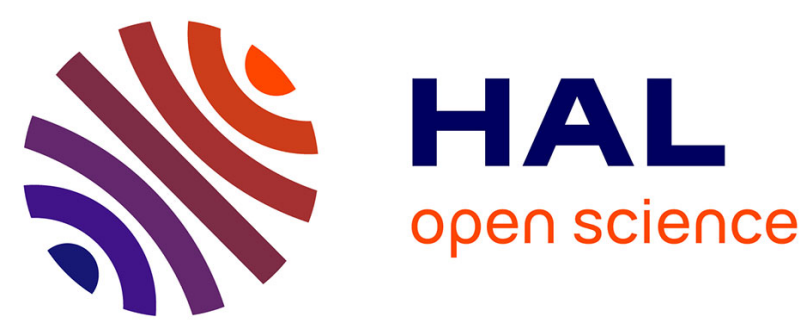

\title{
Nocardamine-Dependent Iron Uptake in Pseudomonas aeruginosa: Exclusive Involvement of the FoxA Outer Membrane Transporter
}

Vincent Normant, Inokentijs Josts, Lauriane Kuhn, Quentin Perraud, Sarah

Fritsch, Philippe Hammann, Gaëtan Mislin, Henning Tidow, Isabelle Schalk

\section{To cite this version:}

Vincent Normant, Inokentijs Josts, Lauriane Kuhn, Quentin Perraud, Sarah Fritsch, et al.. Nocardamine-Dependent Iron Uptake in Pseudomonas aeruginosa : Exclusive Involvement of the FoxA Outer Membrane Transporter. ACS Chemical Biology, 2020, 15 (10), pp.2741-2751. 10.1021/acschembio.0c00535 . hal-03006857

\section{HAL Id: hal-03006857 https://hal.science/hal-03006857}

Submitted on 19 Nov 2020

HAL is a multi-disciplinary open access archive for the deposit and dissemination of scientific research documents, whether they are published or not. The documents may come from teaching and research institutions in France or abroad, or from public or private research centers.
L'archive ouverte pluridisciplinaire HAL, est destinée au dépôt et à la diffusion de documents scientifiques de niveau recherche, publiés ou non, émanant des établissements d'enseignement et de recherche français ou étrangers, des laboratoires publics ou privés. 
This document is confidential and is proprietary to the American Chemical Society and its authors. Do not copy or disclose without written permission. If you have received this item in error, notify the sender and delete all copies.

\section{Nocardamine-dependent iron uptake in Pseudomonas aeruginosa: exclusive involvement of the FoxA outer membrane transporter}

\begin{tabular}{|r|l|}
\hline Journal: & ACS Chemical Biology \\
\hline Manuscript ID & cb-2020-00535j.R1 \\
\hline Manuscript Type: & Article \\
\hline Date Submitted by the & n/a \\
\hline Complete List of Authors: & $\begin{array}{l}\text { Normant, Vincent; Université de Strasbourg, UMR7242 } \\
\text { Josts, Inokentijs; Center for Ultrafast Imaing, , Department of } \\
\text { Chemistry, University of Hamburg } \\
\text { Kuhn, Lauriane; Universite de Strasbourg, Plateforme Proteomique } \\
\text { Strasbourg - Esplanade, Institut de Biologie Moléculaire et Cellulaire } \\
\text { Perraud, Quentin; Université de Strasbourg, UMR7242 } \\
\text { Fritsch, Sarah; Université de Strasbourg, UMR7242 } \\
\text { Hammann, Philippe; Université de Strasbourg, Plateforme Proteomique } \\
\text { Strasbourg - Esplanade, Institut de Biologie Moléculaire et Cellulaire } \\
\text { Mislin, Gaetan; Université de Strasbourg, UMR7242 } \\
\text { Tidow, Henning; University of Hamburg, The Hamburg Centre for } \\
\text { Ultrafast Imaging } \\
\text { Schalk, Isabelle; Université de Strasbourg, UMR7242 }\end{array}$ \\
\hline
\end{tabular}

\section{SCHOLARONE" Manuscripts}


1 Nocardamine-dependent iron uptake in Pseudomonas aeruginosa:

\section{2 exclusive involvement of the FoxA outer membrane transporter}

3

4 Vincent Normant ${ }^{1,2}$, Inokentijs Josts ${ }^{3,4}$, Lauriane Kuhn ${ }^{5}$, Quentin Perraud ${ }^{1,2}$, Sarah Fritsch ${ }^{1,2}$,

5 Philippe Hammann ${ }^{5}$, Gaëtan L. A. Mislin ${ }^{1,2}$, Henning Tidow ${ }^{3,4}$, and Isabelle J. Schalk ${ }^{1,2}$ *

6

$7{ }^{1}$ CNRS, UMR7242, UMR7242, ESBS, Bld Sébastien Brant, F-67412 Illkirch, Strasbourg,

8 France

92 Université de Strasbourg, UMR7242, ESBS, Bld Sébastien Brant, F-67412 Illkirch,

10 Strasbourg, France

$11{ }^{3}$ The Hamburg Centre for Ultrafast Imaging, University of Hamburg, Hamburg, Germany

$12{ }^{4}$ Department of Chemistry, Institute for Biochemistry and Molecular Biology, University of 13 Hamburg, Hamburg, Germany

145 Plateforme Proteomique Strasbourg - Esplanade, Institut de Biologie Moléculaire et 15 Cellulaire, CNRS, FR1589, 15 rue Descartes, F-67084 Strasbourg Cedex, France

$17{ }^{*}$ To whom correspondence should be addressed: isabelle.schalk@unistra.fr. 


\section{ABSTRACT}

2 Iron is a key nutrient for almost all living organisms. Paradoxically, it is poorly soluble and

3 consequently poorly bioavailable. Bacteria have thus developed multiple strategies to access

4 this metal. One of the most common consists of the use of siderophores, small compounds that

5 chelate ferric iron with very high affinity. Many bacteria are able to produce their own

6 siderophores or use those produced by other microorganisms (exosiderophores) in a piracy

7 strategy. Pseudomonas aeruginosa produces two siderophores, pyoverdine and pyochelin, and

8 is also able to use a large panel of exosiderophores. We investigated the ability of $P$. aeruginosa

9 to use nocardamine (NOCA) and ferrioxamine B (DFOB) as exosiderophores under iron-

10 limited planktonic growth conditions. Proteomic and RT-qPCR approaches showed induction

11 of the transcription and expression of the outer membrane transporter FoxA in the presence of

12 NOCA or DFO in the bacterial environment. Expression of the proteins of the heme- or 13 pyoverdine- and pyochelin-dependent iron uptake pathways was not affected by the presence 14 of these two tris-hydroxamate siderophores. ${ }^{55} \mathrm{Fe}$ uptake assays using fox $A$ mutants showed 15 ferri-NOCA to be exclusively transported by FoxA, whereas ferri-DFOB was transported by 16 FoxA and at least one other unidentified transporter. The crystal structure of FoxA complexed 17 with NOCA-Fe revealed very similar siderophore binding sites between NOCA-Fe and DFOB18 Fe. We discuss iron uptake by hydroxamate exosiderophores in P. aeruginosa cells in the light 19 of these results. 


\section{INTRODUCTION}

2 Iron is an essential nutrient for most bacteria. It is used as an enzymatic cofactor and is required

3 for many essential processes; such as deoxynucleotide biosynthesis, DNA replication, and

4 respiration. ${ }^{1}$ Iron can exist in two different oxidation states in biological systems, the ferric $5 \quad\left(\mathrm{Fe}^{3+}\right)$ or ferrous $\left(\mathrm{Fe}^{2+}\right)$ forms, both playing an essential role in biological oxidation-reduction 6 processes. Under aerobic conditions, iron is mostly found in its ferric form, which is poorly 7 soluble and consequently insufficiently bioavailable for microorganisms. Under conditions of 8 infection, this metal is sequestered by host proteins, such as transferrin or lactoferrin, due to the

9 insolubility of ferric iron and toxicity of ferrous iron (Fenton reaction). Thus, bacteria mostly

11 the paucity of available iron and improve its bioavailability, bacteria produce molecules called 12 siderophores, ${ }^{2}$ characterized by a very high affinity for $\mathrm{Fe}^{3+}\left(10^{42} \mathrm{M}^{-1}\right.$ and $10^{32} \mathrm{M}^{-1}$ for infections.

21 In Gram-negative bacteria, upon the capture of iron from the bacterial environment by siderophores, the ferri-siderophore complexes are recognized and transported back into the 23 bacteria by specific outer membrane transporters. ${ }^{5}$ These transporters interact with an inner 24 membrane protein complex of three proteins, TonB, ExbB, and ExbD, providing the energy for ferri-siderophore uptake across the outer membrane. ${ }^{6,7}$ These outer membrane transporters are 
1 thus called TonB-dependent transporters (TBDTs). TBDTs generally contain highly specific

2 siderophore binding sites and thus a given TBDT is able to transport only one siderophore or

3 structurally-related siderophores. ${ }^{5}$ Most bacteria can also use exosiderophores (siderophores

4 produced by other microorganisms) to access iron in a siderophore piracy strategy. ${ }^{8,9} \mathrm{~A}$

5 prerequisite of such a strategy is that the genome of the pirate bacteria contains genes encoding

6 TBDTs that are able to recognize and transport the exosiderophores produced by the hacked

7 bacteria. In addition, it is necessary for the pirate bacteria to phenotypically adapt their

8 expression of the corresponding TBDTs and other accessory proteins to gain access to iron

9 from the exosiderophores produced by the hacked microorganism. ${ }^{9}$

10 The opportunistic human pathogen Pseudomonas aeruginosa produces two siderophores: 11 pyoverdine (PVD), considered as a major siderophore, and pyochelin $(\mathrm{PCH})$, considered as a 12 secondary siderophore. ${ }^{10}$ The production of these siderophores occurs in parallel with the 13 expression of the specific TBDTs FpvA and FpvB for PVD ${ }^{11,12}$ and FptA for PCH. ${ }^{13}$ The 14 genome of $P$. aeruginosa also contains three genes encoding TBDTs involved in heme uptake 15 pathways (hasR, phuR and hur -previously called $h x u A-)^{14-16}$ and various genes encoding 16 TBDTs involved in ferric-iron acquisition by exosiderophores. $P$. aeruginosa can acquire iron 17 from the catechol exosiderophore enterobactin via the TBDTs PfeA and PirA , ${ }^{17-20}$ and 18 vibriobactin via FvbA. $^{21}$ It can also use the exosiderophores mycobactin and 19 carboximycobactin via the TBDT FemA, ${ }^{22}$ aerobactin, rhizobactin, and schizokinen by ChtA, ${ }^{23}$ 20 and citrate by FecA. ${ }^{24}$ Hydroxamate siderophores are also used by $P$. aeruginosa, along with 21 ferrioxamine B (DFOB), transported by FoxA, ${ }^{25,26}$ and ferrichrome (FRC), transported by 22 FiuA. $^{25}$ DFOB (Figure 1B) is produced by the soil bacterium Streptomyces pilosus ${ }^{27}$ and FRC 23 (Figure 1C) by various fungi, such as Ustilago, Aspergillus, and Penicillium. ${ }^{28}$

24 Bacteria are able to sense the presence of such exosiderophores by either sigma or anti-sigma 25 factors, two-component systems, or transcriptional regulators of the AraC family. ${ }^{22,29-31}$ Having 
1 detected the presence of ferri-exosiderophores, these transcriptional regulators activate the

2 transcription of the corresponding TBDT for iron acquisition. . $^{9,22,29-32}$

3 Here, we investigated the ability of $P$. aeruginosa to use nocardamine (NOCA, Figure 1A) as 4 an exosiderophore. NOCA, also called desferrioxamine E, is a cyclic tris-hydroxamate 5 siderophore related to DFOB, with a higher affinity for iron: $10^{32} \mathrm{M}^{-1}$ for NOCA and $10^{30} \mathrm{M}^{-1}$ 6 for $\mathrm{DFOB}^{33}$ (Figure 1). NOCA is synthesized by various actinomycetes, such as Streptomyces, 7 Nocardia, and Micromonospora, ${ }^{34}$ and bacteria, such as Streptomyces griseus, ${ }^{35}$ Pseudomonas 8 stutzeri, ${ }^{36}$ and Enterobacter agglomerans. ${ }^{37}$ We show that the presence of NOCA in the $P$. 9 aeruginosa environment strongly induces the transcription and expression of fox $A$ with the 10 same efficiency as DFOB. We demonstrate, using ${ }^{55} \mathrm{Fe}$, that NOCA- ${ }^{55} \mathrm{Fe}$ is exclusively 11 transported by the TBDT FoxA, whereas DFOB uses, in addition to FoxA, at least one other 12 transporter. We also determined the crystal structure of FoxA complexed with ferri-NOCA, 13 revealing a siderophore-binding site very similar to that of DFOB. 


\section{RESULTS AND DISCUSSION}

\section{The presence of NOCA induces the transcription and expression of the TBDT fox $A$ in $P$.}

3 aeruginosa cells. $P$. aeruginosa can sense the presence of iron-loaded exosiderophores in its

4 environment via AraC regulators, sigma factors, or two-component systems, resulting in the

5 induction of the transcription and expression of the corresponding TBDTs. ${ }^{9,22,29-32}$ We grew $P$.

6 aeruginosa PAO1 in iron-restricted medium (CAA medium), with or without $10 \mu \mathrm{M}$ NOCA,

7 and analyzed the bacteria by proteomics to identify the TBDTs and any other proteins involved

8 in iron acquisition by NOCA (Figure 2).

9 In the presence of NOCA, only the expression of the TBDT FoxA was strongly induced, 10 showing a $\log 26.37$-fold increase (Figure $2 \mathrm{~A}$ ). This result was confirmed by RT-qPCR, which 11 showed a $\log 24.46$-fold induction of transcription of foxA gene in the presence of NOCA 12 (Figure 3). We repeated the same proteomic and qRT-PCR experiments with DFOB, and 13 observed similar induction of fox $A$ transcription and expression (Figures 2 and 3), as previously 14 shown. ${ }^{22}$ The induction of transcription and expression of fox $A$ was of the same intensity for 15 both exosiderophores.

16 In conclusion, fox $A$ transcription and expression is induced by both NOCA and DFOB, showing 17 that these two siderophores use this TBDT to transport iron from the environment into the $P$. 18 aeruginosa periplasm. Previous studies, using exactly the same experimental approach and conditions, showed that the presence of the tris-hydroxamate exosiderophore FRC in the $P$. 20 aeruginosa environment induces the expression of the TBDT FiuA. ${ }^{9}$ These sensing 21 mechanisms involve cell surface signaling that involves the TBDT itself and coupled sigma and 22 anti-sigma factors FoxR/FoxI and FiuR/FiuI. ${ }^{22,25}$ The various changes in protein conformation 23 and the protein interactions involved in these signaling cascades have been described in more 24 detail for the PVD pathway, with the FpvR/PvdS or FpvR/FpvI sigma/anti sigma factors. 25 Binding of iron-loaded PVD to the TBDT FpvA induces movement of the periplasmic N- 
1 terminal domain of FpvA interacting with the periplasmic part of the anti-sigma factor FpvR.

2 This interaction results in FpvR proteolysis by two enzymes and release of the two sigma factors

3 PvdS and FpvI, which are normally sequestered by FpvR, into the cytoplasm. PvdS and FpvI

4 then initiate transcription of the $f p v A$ gene and all genes encoding proteins involved in iron 5 acquisition by PVD. ${ }^{12,31,41-47}$ Certainly, a very similar mechanism is involved in the regulation 6 of the transcription of fiuA by ferri-FRC and foxA by NOCA and DFOB.

Tris-hydroxamate siderophores do not strongly repress the expression or transcription of proteins involved in the PVD and PCH pathways. Previous studies have shown that the presence of catechol siderophores, such as enterobactin and vibriobactin, significantly represses 11 the expression of the proteins of the PCH pathway and, to a lower extent, those of the PVD 12 pathway. ${ }^{9}$ The expression of the proteins of the PCH and PVD pathways was not significantly 13 repressed by the presence of NOCA or DFOB (Figures 2D and 2E). This result was confirmed 14 by RT-qPCR by following the transcription of the mRNAs encoding $f p t A$ and $f p v A$ (the TBDTs of PCH and PVD, respectively) in the presence of NOCA (Figure 3A) or DFOB (Figure 3B). There was also no effect on the expression of the mRNA or proteins of heme-uptake pathways 17 (hasR and phuR TBDTs, proteomic data and Figure 3). A very similar phenotypic adaptation 18 was previously described for $P$. aeruginosa cells grown in the presence of FRC, ${ }^{9}$ leading to the 19 conclusion that hydroxamate siderophores, such as NOCA, DFOB, and FRC do not repress the expression of the proteins of the $\mathrm{PCH}-$ and PVD-dependent iron uptake pathways. Non21 repression of the expression of the PVD and $\mathrm{PCH}$ pathways has also been observed in the presence of yersiniabactin (a mixed siderophore produced by Yersinia pestis). ${ }^{9}$ These results 23 were previously explained by the different affinities of the siderophores for ferric iron and 24 consequently their ability to scavenge iron from the environment. The catechol siderophores, 25 like enterobactin, show the highest affinity for ferric iron among siderophores, ${ }^{3}$ with a $\mathrm{K}_{\mathrm{a}}$ of 
$1 \quad 10^{42} \mathrm{M}^{-1}$ for enterobactin, much higher than the affinities of PVD and $\mathrm{PCH}$, the siderophores

2 produced by P. aeruginosa $\left(10^{18} \mathrm{M}^{-2}\right.$ for $\mathrm{PCH}^{48}$ and $10^{32} \mathrm{M}^{-1}$ for $\left.\mathrm{PVD}{ }^{49}\right)$. Consequently, more

3 ferric iron-loaded catechol siderophores are formed in the bacterial environment than ferri-PCH

4 and ferri-PVD. This results in lower expression of the PVD and PCH uptake pathways because

5 of lower activation of the transcriptional regulators AraC for the $\mathrm{PCH}$ pathway and the anti6 sigma/sigma system for PVD. ${ }^{30,31}$ Tris-hydroxamate siderophores compete less for iron 7 chelation than catecholate siderophores or PVD, which explains the absence of repression in 8 the expression of proteins of the PVD pathway and even the $\mathrm{PCH}$ pathway when bacteria are 9 grown in the presence of such exosiderophores.

11 Ferri-NOCA is transported only by the TBDT FoxA in $\boldsymbol{P}$. aeruginosa. fox $A$ was the only 12 TBDT for which the transcription and expression was induced by the presence of NOCA. We 13 thus next investigated the effect of $f o x A$ deletion on ${ }^{55} \mathrm{Fe}$ acquisition in $P$. aeruginosa cells in 14 the presence of NOCA. We used a strain of $P$. aeruginosa unable to produce the siderophores $15 \mathrm{PVD}$ and $\mathrm{PCH}(\Delta p v d F \Delta p c h A$ in Supplementary Table 1$)$ to avoid any ${ }^{55} \mathrm{Fe}$ uptake by these two 16 siderophores. The bacteria were grown in CAA medium and then incubated in the presence of 17 NOCA $-{ }^{55} \mathrm{Fe}$. Aliquots were removed at various timepoints, the bacteria pelleted, and the 18 radioactivity in the bacteria counted. The $\triangle p v d F \Delta p c h A$ strain was able to acquire ${ }^{55} \mathrm{Fe}$ via 19 NOCA, with an uptake rate of $335.96 \pm 59.12 \mathrm{pmol} / \mathrm{ml} / \mathrm{OD}_{600 \mathrm{~nm}}$ (Figure $4 \mathrm{~A}$ ). The deletion of 20 foxA ( $\triangle p v d F \triangle p c h A \triangle$ foxA mutant) completely abolished the ability of the bacteria to assimilate $21{ }^{55} \mathrm{Fe}$ in the presence of NOCA, similarly to carbonyl cyanide- $m$-chlorophenylhydrazone 22 (CCCP) treatment of the bacteria. CCCP is an inhibitor of the inner membrane proton motive 23 force. It is well known that the incubation of bacteria with CCCP abolishes all TonB-dependent 24 transport. ${ }^{50}$ Overall, these results demonstrate that ${ }^{55} \mathrm{Fe}$ is transported in P. aeruginosa cells in 
1 the presence of NOCA and that such transport is exclusively dependent on FoxA for iron uptake 2 across the outer membrane.

3 We also demonstrated the exclusive involvement of FoxA in ferri-NOCA uptake using a growth 4 assay. The PVD- and PCH-deficient strain $(\triangle p v d F \Delta p c h A)$ and its corresponding fox $A$ mutant $5(\triangle p v d F \triangle p c h A \Delta f o x A)$ were grown in CAA medium, which contains approximately $20 \mathrm{nM}$ iron 6 according to ICP-AES measurements. ${ }^{51}$ Growth was carried out in the presence or absence of $710 \mu \mathrm{M}$ NOCA (Figure 5A and 5B), which would chelate all the iron of the medium. $8 \Delta p v d F \triangle p c h A$ cells grew in the presence of NOCA, showing that they could access iron via 9 NOCA. On the contrary, the foxA deletion mutant $\triangle p v d F \Delta p c h A \Delta f o x A$ was unable to grow in 10 the presence of NOCA, confirming that FoxA is the only TBDT present in the P. aeruginosa 11 genome that is able to transport ferri-NOCA complexes.

Ferri-DFOB uptake in $P$. aeruginosa involves FoxA and at least one other unidentified

14 TBDT. DFOB induced fox $A$ transcription and expression when $P$. aeruginosa cells were grown 15 under iron-restricted conditions in the presence of this exosiderophore (Figures 2 and 3). We 16 used the same ${ }^{55} \mathrm{Fe}$ uptake assay as above to investigate iron acquisition via DFOB in $P$. 17 aeruginosa $\triangle p v d F \Delta p c h A$ cells (Figure $4 \mathrm{~B}$ ). Uptake of $220.83 \pm 47.04 \mathrm{pmol} / \mathrm{ml} / \mathrm{OD}_{600 \mathrm{~nm}}$ of ${ }^{55} \mathrm{Fe}$ 18 was observed in the presence of DFOB. This uptake is abolished in the presence of CCCP 19 indicating that it is dependent on the proton motive force of the inner membrane and completely 20 relies on TBDTs. Deletion of foxA induced a $27 \%$ decrease in ${ }^{55} \mathrm{Fe}$ uptake by $21 \Delta p v d F \Delta p c h A \Delta f o x A$ cells $\left(161.56 \pm 56.93 \mathrm{pmol} / \mathrm{ml} / \mathrm{OD}_{600 \mathrm{~nm}}\right)$ relative that by $\triangle p v d F \Delta p c h A$ cells. 22 Such partial inhibition of ${ }^{55} \mathrm{Fe}$ uptake indicates that FoxA is also involved in iron uptake by 23 DFOB, but that it is not the only TBDT involved. Deletion of fiuA ( $\triangle p v d F \triangle p c h A \Delta f i u A$ strain) 24 did not affect ${ }^{55} \mathrm{Fe}$ transport by DFOB $\left(213.96 \pm 10.88 \mathrm{pmol} / \mathrm{ml} / \mathrm{OD}_{600 \mathrm{~nm}}{ }^{55} \mathrm{Fe}\right.$ transport after 25180 minutes), indicating that this transporter plays no role in iron acquisition by DFOB in $P$. 
1 aeruginosa cells. Growth of $\triangle p v d F \Delta p c h A$ and $\triangle p v d F \Delta p c h A \Delta f o x A$ cells in CAA medium in the

2 presence of $10 \mu \mathrm{M}$ DFOB (Figure 5C) resulted in slightly less (9\%) growth of the fox $A$ mutant

3 than $\triangle p v d F \Delta p c h A$ cells, confirming that FoxA is not the only TBDT involved in iron

4 assimilation by this exosiderophore. At least one other TBDT is involved and takes over uptake

5 in the absence of FoxA expression.

6 Since this TBDT may have its expression induced only when FoxA is absent and in a strain

7 unable to produce pyoverdine and pyochelin, P. aeruginosa $\Delta p v d F \Delta p c h A \Delta f i u A \Delta f o x A$ cells

8 were grown in iron-restricted medium (CAA medium), with or without $10 \mu \mathrm{M} \mathrm{DFOB}$, and

9 analyzed by proteomics (Supplementary Figure 2). The data show that no other TBDT has its

10 expression induced in a fiuA and fox $A$ mutant, suggesting that the second TBDT involved in

11 iron acquisition by DFOB has not its transcription and expression regulated by the presence of

12 DFOB in the growth media. We also compared the expression of the different TBDTs in the $13 \Delta p v d F \Delta p c h A \Delta f i u A \Delta f o x A$ versus PAO1 in the absence of any siderophore in the growth media, 14 and no TBDT having its expression induced was detected (Supplementary Figure 3). $P$. 15 aeruginosa has in its genome 35 genes coding for TBDTs. ${ }^{52}$ Among them, 17 have their 16 transcription negatively regulated by Fur and positively by the presence in the growth media of 17 the siderophore transported via either sigma and anti-sigma factors, AraC regulators or two18 component systems. ${ }^{52} 18$ genes coding for TBDTs have their transcription only regulated by 19 Fur with no positive auto-regulating loop and for 12 of them the siderophore or molecule 20 transported has not been identified yet. These 12 TBDTs are all possible candidates for the 21 import of iron loaded DFOB.

22 Overall, these data show that iron assimilation via DFOB does not involve the TBDT FiuA, but 23 FoxA and at least one other unidentified TBDT, of which the expression is not regulated by the 24 presence of this exosiderophore (not detected by the proteomic approach described above). 
1 FoxA is not involved in ${ }^{55} \mathrm{Fe}$ uptake via FRC in $\boldsymbol{P}$. aeruginosa. Previous studies, carried out

2 under the same conditions as described here, have shown that FRC induces fiuA expression

3 when $P$. aeruginosa cells are grown under iron-restricted conditions in the presence of this

4 exosiderophore ${ }^{9}$. As above, we followed ${ }^{55} \mathrm{Fe}$ uptake to investigate iron acquisition via FRC in

$5 \quad$ P. aeruginosa $\triangle p v d F \Delta p c h A$ cells (Figure $4 \mathrm{C}$ ). Uptake of $110.81 \pm 16.77 \mathrm{pmol} / \mathrm{ml} / \mathrm{OD}_{600 \mathrm{~nm}}$ of

$6{ }^{55} \mathrm{Fe}$ occurred in the presence of FRC, indicating that FRC is three times less efficient than

$7 \quad$ NOCA and two times less efficient than DFOB in transporting iron in P. aeruginosa cells. This

8 uptake is also abolished in the presence of CCCP indicating that it relies on TBDTs. ${ }^{50}$ Mutation

9 of $f i u A$ resulted in a $20 \%$ decrease in ${ }^{55} \mathrm{Fe}$ acquisition by $\mathrm{FRC}\left(88.07 \pm 5.89 \mathrm{pmol} / \mathrm{ml} / \mathrm{OD}_{600 \mathrm{~nm}}\right)$

10 after 180 min of uptake, proving that FiuA can transport FRC-Fe ${ }^{55}$ complexes into the pathogen.

11 In contrast, there was no significant difference in $\mathrm{FRC}-{ }^{55} \mathrm{Fe}$ acquisition between $\Delta p v d F \Delta p c h A$

12 and $\triangle p v d F \Delta p c h A \Delta f o x A$ and between $\triangle p v d F \Delta p c h A \Delta f i u A$ and $\triangle p v d F \Delta p c h A \Delta f i u A \Delta f o x A$ cells

13 (Figure 4C), indicating that FoxA is apparently not involved in iron acquisition by FRC. The

14 growth of $\triangle p v d F \Delta p c h A$ and $\triangle p v d F \Delta p c h A \Delta f i u A$ cells in CAA medium in the presence of $10 \mu \mathrm{M}$ 15 FRC showed a low level (14\%) of growth inhibition (Figure 5D and 5E), confirming that FiuA 16 is not the only TBDT involved in iron assimilation by FRC. In order to identify this transporter, $17 P$. aeruginosa cells deleted for both foxA and fiuA ( $\triangle p v d F \Delta p c h A \Delta f i u A \Delta$ foxA) were grown in

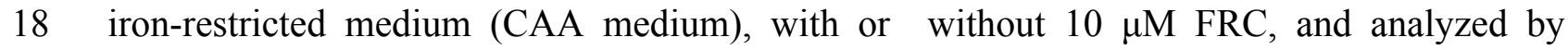
19 proteomics (Supplementary Figure 2). The data show, as above for DFOB, that no other TBDT 20 has its expression induced in a fiu $A$ and fox $A$ mutant in the presence of FCR.

21 In conclusion, FoxA plays no role in iron uptake via FRC, but FiuA is involved, and at least 22 one other TBDT, of which the transcription and expression is not induced by the presence of 23 FRC in the growth media. 
1 Structure of FoxA complexed with NOCA. DFOB and NOCA are structurally related

2 siderophores. We investigated the interactions between FoxA and NOCA by determining the

3 crystal structure of the complex to $2.95 \AA$ A resolution (Figure 6). The electron density for the

4 siderophore was present, as shown by Polder omit maps, revealing a cloverleaf-like shape of

5 the cyclic NOCA within the binding pocket of FoxA (Figure 6). Our crystal structure of the

6 FoxA-NOCA complex was highly similar to the previously determined apo FoxA (r.m.s.d 0.53

$7 \AA$ ) and FoxA-DFOB structures (r.m.s.d. $0.38 \AA$ ) (Supplementary Figure 4). NOCA occupies an

8 internal cavity exposed to the extracellular space, forming three hydrogen bonds to the side

9 chains facing the binding site (mainly H374, Y218, Y805), with additional stabilizing contacts

10 mediated by the surrounding aromatic side chains. Comparison of the complexes formed by

11 FoxA with NOCA-Fe and DFOB-Fe shows that the mode of siderophore coordination is

12 essentially the same, albeit with fewer H-bonds between FoxA and NOCA-Fe than with DFOB-

13 Fe (Supplementary Figure 5). The position of the ferri-NOCA and ferri-DFOB siderophores

14 are almost perfectly superimposed based on the position of the Fe atoms (Figure 7A).

15 We investigated the affinity of iron-loaded NOCA for purified FoxA by tryptophan 16 fluorescence quenching. ${ }^{26}$ Titration of ferri-NOCA into purified FoxA led to concentration17 dependent quenching of Trp fluorescence and showed the dissociation constant $\left(\mathrm{K}_{\mathrm{d}}\right)$ to be 178 $18 \pm 16 \mathrm{nM}$, with a 1:1 stoichiometry (Figure 7B), slightly higher than the previously reported $\mathrm{K}_{\mathrm{d}}$ 19 of $100 \pm 10 \mathrm{nM}$ of ferri-DFOB for FoxA. ${ }^{26}$

20 It is surprising how perfectly the position of the ferri-NOCA and ferri-DFOB siderophores in 21 FoxA binding site superimpose, with the Fe atoms located at exactly the same position in both 22 complexes. The structure of FoxA was previously crystallized in the apo-form and complexed 23 with DFOB and the periplasmic domain of TonB. ${ }^{26}$ These structures and biophysical interaction 24 studies showed that ferri-DFOB binds to the transporter in a two-step TonB-binding 25 mechanism, which must also be true for ferri-NOCA binding. ${ }^{26}$ As both ferri-NOCA and ferri- 
1 DFOB complexes share a very similar mode of binding to FoxA, it is not surprising that they 2 activate the signaling pathway involving FoxR/FoxI with similar efficiency for the transcription 3 and expression of FoxA.

4

5 Conclusion. In conclusion, we demonstrate that at least two TBDTs, FoxA and FiuA, are 6 involved in iron acquisition by tris-hydroxamate siderophores in P. aeruginosa cells. FiuA 7 imports ferri-FRC complexes across the outer membrane and FoxA, ferri-NOCA, and ferri8 DFOB complexes. The crystal structure of FoxA shows a very similar binding mode for ferri9 NOCA and ferri-DFOB to a common binding site and fluorescence titration experiments gave 10 binding affinities of the same order of magnitude. These data offer new insights into the 11 complexity and specificity of the mechanisms involved in iron acquisition by tris-hydroxamate 12 exosiderophores. They also show how P. aeruginosa adapts the expression of its various 13 TBDTS in the presence of such exosiderophores. Siderophore-dependent iron uptake pathways 14 are more and more considered as promising gates for the uptake of antibiotics in a Trojan horse 15 strategy. The ability of $P$. aeruginosa cells to sense the presence of NOCA and the resulting 16 highly efficient iron uptake by NOCA are potential assets for the use of NOCA analogues in 17 antibiotic vectorization strategies. 


\section{METHODS}

2 Chemicals. Desferrioxamine B (DFOB), ferrichrome (FRC), and the protonophore carbonyl

3 cyanide $m$-chlorophenylhydrazone (CCCP) were purchased from Sigma-Aldrich and ${ }^{55} \mathrm{FeCl}_{3}$

4 was purchased from Perkin Elmer. NOCA was purified as previously described. ${ }^{53}$

6 Bacterial strains and growth conditions. The $P$. aeruginosa PAO1 strains used in this study

7 are listed in Table SM1. When grown in iron restricted medium, bacteria were first grown in

8 LB medium overnight at $30^{\circ} \mathrm{C}$. Afterwards, they were washed and resuspended in iron-deficient

9 CAA (casamino acid) medium, containing 5 $\mathrm{g} \mathrm{L}^{-1}$ low-iron CAA (Difco), $1.46 \mathrm{~g} \mathrm{~L}^{-1} \mathrm{~K}_{2} \mathrm{HPO}_{4}$

$103 \mathrm{H}_{2} \mathrm{O}$, and $0.25 \mathrm{~g} \mathrm{~L}^{-1} \mathrm{MgSO}_{4} 7 \mathrm{H}_{2} \mathrm{O}$, and grown overnight at $30^{\circ} \mathrm{C}$. To monitor growth in the

11 presence of siderophores, cells were resuspended again in fresh CAA medium at an optical

12 density of $\mathrm{OD}_{600 \mathrm{~nm}}=0.1$ with or without $10 \mu \mathrm{M}$ DFOB, NOCA, or FRC in 96 well plates.

13 Plates were incubated at $30^{\circ} \mathrm{C}$, with shaking every $15 \mathrm{~min}$, in a microplate reader (Infinite

14 M200, Tecan). Growth was followed by measuring the optical density $\left(\mathrm{OD}_{600 \mathrm{~nm}}\right)$ every $30 \mathrm{~min}$, 15 for $20 \mathrm{~h}$.

17 Construction of fiuA and foxA mutants. Enzymes were obtained from ThermoFisher 18 Scientific. Escherichia coli TOP10 (Invitrogen) was used as the host strain for the plasmids.

19 Plasmid construction and primers were as described previously. ${ }^{9}$ Briefly, 1,400 -bp inserts made 20 up of the flanking sequences of either foxA or fiuA were cloned into a pEXG2 plasmid using a 21 blunt-end ligation strategy. Plasmids were sequenced before being used to generate 22 chromosomal mutations in a $P$. aeruginosa PAO1 $\Delta p v d F \Delta p c h A$ strain (Supplementary Table 23 2) as previously described. Recombinant clones were isolated before being verified by PCR 24 and Sanger sequencing. ${ }^{9}$ 
$1 \boldsymbol{R N A}$ extraction. Bacteria were first grown in LB medium overnight at $30^{\circ} \mathrm{C}$. Afterwards, they 2 were washed and resuspended in CAA medium and grown over night. After growth, cells were 3 washed, and resuspended at an $\mathrm{OD}_{600 \mathrm{~nm}}$ of 0.1 in fresh CAA medium with or without one of 4 the tested siderophores $(10 \mu \mathrm{M})$. Cells were cultivated at $30^{\circ} \mathrm{C}$ for $8 \mathrm{~h}$. Afterwards, $2.5 \times 10^{8}$ 5 cells were mixed with two volumes of RNAprotect Bacteria Reagent (Qiagen). Samples were 6 lysed in Tris-EDTA pH 8.0 containing $15 \mathrm{mg} / \mathrm{ml}$ lysozyme (Sigma-Aldrich) for $15 \mathrm{~min}$ at $25^{\circ} \mathrm{C}$. 7 Then, lysates were homogenized using a QIAshredder kit (Quiagen) and total RNA extracted 8 using an RNeasy mini kit (Quiagen). After treatment with DNase (RNase-Free DNase Set, 9 Qiagen), RNA was purified with an RNeasy Mini Elute cleanup kit (Qiagen).

$11 \boldsymbol{R} \boldsymbol{T}-\boldsymbol{q} P \boldsymbol{C} \boldsymbol{R}$ analysis. RNA (1 $\mu \mathrm{g})$ was reversed-transcribed using a High Capacity RNA to cDNA 12 kit, in accordance with the manufacturer's instructions (Applied Biosystems). Gene expression 13 was measured in a SpetOne Plus Instrument (Applied Biosystems) using Power Sybr Green 14 PCR Master Mix (Applied Biosystems) and the appropriate primers (listed in Supplementary 15 Table 3). The expression of $u v r D$ was used as an internal control. The transcript levels were 16 normalized with respect to those for $u v r D$ and expressed as base two logarithms of the ratio 17 (fold-change) relative to the reference conditions.

Iron uptake. Bacteria were grown as for RNA extraction. Complexes of siderophore- ${ }^{55} \mathrm{Fe}$ were prepared as previously described ${ }^{32}$ in $50 \mathrm{mM}$ Tris- $\mathrm{HCl} \mathrm{pH} 8.0$ buffer with a siderophore:iron 21 ratio of 20:1 and as described previously. ${ }^{9}$

Proteomic analysis. Bacteria were grown as for RNA extraction. The cells $\left(5 \times 10^{8}\right)$ were 24 harvested and used for proteomic analysis. Each sample was prepared in biological triplicate 25 for each cell-culture condition and the data analyzed as described previously. ${ }^{9}$ The MS data 
1 were deposited in the ProteomeXchange Consortium database via the PRIDE $^{54}$ partner

2 repository with the dataset identifier PXD020868 (Project DOI: 10.6019/PXD020868).

3 Reviewer account details: Username: reviewer99826@ebi.ac.uk Password: KTZIIS5w.

4

5

6 previously described. ${ }^{26}$

7

8 Crystallization and structure determination. For crystallization, FoxA was mixed with a 3- to

9 4-fold excess NOCA-Fe dissolved in 100\% DMSO and set on ice for approximately $30 \mathrm{~min}$.

Crystals of FoxA-NOCA-Fe complex were grown in $1.8 \mathrm{M}$ ammonium sulfate, $0.1 \mathrm{M}$ sodium cocadylate $\mathrm{pH} 6.5,0.05 \mathrm{M} \mathrm{NaCl}$, cryo-protected by the step-wise addition of glycerol to a final concentration of $18-20 \%(\mathrm{v} / \mathrm{v})$, and immediately harvested.

X-ray diffraction data were collected at the P14 beamline EMBL, Hamburg. All data were processed with $\mathrm{XDS}^{55}$ and reduced using AIMLESS. ${ }^{56,57}$ Due to diffraction anisotropy, the StarANISO server ${ }^{58}$ was used to perform anisotropy correction of the data. Crystals belonged to the $\mathrm{P}_{2} 21$ space group, as in the previously determined FoxA-DFOB-Fe structure. ${ }^{26}$ The structure was solved using molecular replacement in Phaser ${ }^{59}$ using apo FoxA (pdb: 6I96) as the search model and refined to $2.95 \AA$ using REFMAC5. ${ }^{60,61}$ The refinement strategy involved TLS and jelly-body settings. All data collection and refinement statistics are summarized in Table 1. Coordinates have been deposited in the Protein Data Bank (pdb: 6Z8A). Figures were prepared using Pymol and UCSF Chimera.

Tryptophan fluorescence quenching experiments. The dissociation constant of NOCA-Fe from FoxA was determined by tryptophan fluorescence quenching using exactly the same protocol as that previously described. ${ }^{26}$ 


\section{ACKNOWLEDGMENTS}

2 We are grateful to the staff at the P14 beamline (EMBL, Hamburg) and acknowledge access to 3 the Sample Preparation and Characterization (SPC) Facility of the EMBL. This work was 4 partially funded by the Centre National de la Recherche Scientifique and grants from the 5 associations Vaincre la Mucoviscidose and Gregory Lemarchal (French associations against $6 \quad$ cystic fibrosis) and the Agence Nationale pour la Recherche (VECTRIUM project, ANR 197 CE18-0011-02). V Normant held a fellowship from the Fondation pour la Recherche Médicale 8 and Q Perraud from the associations Vaincre la Mucoviscidose and Gregory Lemarchal. The 9 mass spectrometry instrumentation at the IBMC was funded by the University of Strasbourg, 10 IdEx "Equipement mi-lourd" 2015. The equipment at the IPHC was partially funded by the 11 French Proteomics Infrastructure (ProFI; ANR-10-INSB-08-03).

12

13 Supporting Information Available: This material is available free of charge via the Internet. 14 15 16 


\section{REFERENCE}

2 (1) Andreini, C.; Bertini, I.; Cavallaro, G.; Holliday, G. L.; Thornton, J. M. Metal ions in biological catalysis: from enzyme databases to general principles. $J$ Biol Inorg Chem 2008, $13(8), 1205-1218$.

(2) Hider, R. C.; Kong, X. Chemistry and biology of siderophores. Natural product reports 2011, 27 (5), 637-657. https://doi.org/10.1039/b906679a.

(3) Loomis, L.; Raymond, K. N. Solution equilibria of enterobactin complexes. Inorg. Chem. 1991, 30, 906-911.

(4) Albrecht-Gary, A. M.; Crumbliss, A. L. Coordination chemistry of siderophores: thermodynamics and kinetics of iron chelation and release. Metal Ions Biological Systems 1998, 35, 239-327.

(5) Schalk, I. J.; Mislin, G. L. A.; Brillet, K. Structure, function and binding selectivity and stereoselectivity of siderophore-iron outer membrane transporters. Curr Top Membr 2012, 69, 37-66. https://doi.org/10.1016/B978-0-12-394390-3.00002-1.

(6) Krewulak, K. D.; Vogel, H. J. TonB or not TonB: Is that the question? Biochemistry and cell biology 2011, 89 (2), 87-97. https://doi.org/10.1139/o10-141.

(7) Celia, H.; Noinaj, N.; Buchanan, S. K. Structure and stoichiometry of the Ton molecular motor. Int J Mol Sci 2020, 21 (2). https://doi.org/10.3390/ijms21020375.

(8) Barber, M. F.; Elde, N. C. Buried treasure: evolutionary perspectives on microbial iron piracy. Trends Genet. 2015, 31 (11), 627-636. https://doi.org/10.1016/j.tig.2015.09.001.

(9) Perraud, Q.; Cantero, P.; Roche, B.; Gasser, V.; Normant, V. P.; Kuhn, L.; Hammann, P.; Mislin, G. L. A.; Ehret-Sabatier, L.; Schalk, I. J. Phenotypic adaption of Pseudomonas aeruginosa by hacking siderophores produced by other microorganisms. Mol. Cell Proteomics 2020, 19(4), 589-607. https://doi.org/10.1074/mcp.RA119.001829. 
1 (10) Schalk, I. J.; Rigouin, C.; Godet, J. An overview of siderophore biosynthesis among 2 fluorescent Pseudomonads and new insights into their complex cellular organization. Environ. Microbiol. 2020, 22 (4), 1447-1466. https://doi.org/10.1111/1462-2920.14937.

4 (11) Ghysels, B.; Dieu, B. T.; Beatson, S. A.; Pirnay, J. P.; Ochsner, U. A.; Vasil, M. L.; Cornelis, P. FpvB, an alternative type I ferripyoverdine receptor of Pseudomonas aeruginosa. Microbiology 2004, 150 (Pt 6), 1671-1680.

(12) Brillet, K.; Journet, L.; Celia, H.; Paulus, L.; Stahl, A.; Pattus, F.; Cobessi, D. A $\beta$-strand lock-exchange for signal transduction in TonB-dependent transducers on the basis of a common structural motif. Structure 2007, 15, 1383-1391.

(13) Cobessi, D.; Celia, H.; Pattus, F. Crystallization and X-ray diffraction analyses of the

(16) Atanaskovic, I.; Mosbahi, K.; Sharp, C.; Housden, N. G.; Kaminska, R.; Walker, D.;

(14) Cornelis, P.; Bodilis, J. A survey of TonB-dependent receptors in fluorescent Pseudomonads. Environmental microbiology reports 2009, 1 (4), 256-262. https://doi.org/10.1111/j.1758-2229.2009.00041.x.

(15) Smith, A. D.; Wilks, A. Differential contributions of the outer membrane receptors PhuR and HasR to Heme acquisition in Pseudomonas aeruginosa. J. Biol. Chem. 2015, 290 (12), 7756-7766. https://doi.org/10.1074/jbc.M114.633495.

Kleanthous, C. Targeted killing of Pseudomonas aeruginosa by pyocin G occurs via the hemin transporter Hur. Journal of Molecular Biology 2020, 432 (13), 3869-3880. https://doi.org/10.1016/j.jmb.2020.04.020.

(17) Poole, K.; Young, L.; Neshat, S. Enterobactin-mediated iron transport in Pseudomonas aeruginosa. J Bacteriol 1990, 172 (12), 6991-6996. 
1 (18) Ghysels, B.; Ochsner, U.; Mollman, U.; Heinisch, L.; Vasil, M.; Cornelis, P.; Matthijs, S. The Pseudomonas aeruginosa PirA gene encodes a second receptor for ferrienterobactin and synthetic catecholate analogues. FEMS microbiology letters $\mathbf{2 0 0 5}$, $246(2), 167-174$.

(19) Moynié, L.; Luscher, A.; Rolo, D.; Pletzer, D.; Tortajada, A.; Weingart, H.; Braun, Y.; Page, M. G. P.; Naismith, J. H.; Köhler, T. Structure and function of the PiuA and PirA siderophore-drug receptors from Pseudomonas aeruginosa and Acinetobacter baumannii. Antimicrob. Agents Chemother. 2017, 61 https://doi.org/10.1128/AAC.02531-16.

(20) Moynie, L.; Milenkovic, S.; Malloci, G.; Mislin, G. L. A.; Baco, E.; Gasser, V.; Schalk, I. J.; Ceccarelli, M.; Naismith, J. H. The complex of ferric-enterobactin with its transporter suggests a multi-step conformationally coupled process of uptake. submitted to Nature Com. 2019, $10(1), 3673-3687$. https:// doi: 10.1038/s41467-019-11508-y.

(21) Elias, S.; Degtyar, E.; Banin, E. FvbA Is required for vibriobactin utilization in Pseudomonas aeruginosa. Microbiology 2011, 157 (Pt 7), 2172-2180. https://doi.org/10.1099/mic.0.044768-0.

(22) Llamas, M. A.; Mooij, M. J.; Sparrius, M.; Vandenbroucke-Grauls, C. M.; Ratledge, C.; Bitter, W. Characterization of five novel Pseudomonas aeruginosa cell-surface signalling systems. Molecular microbiology 2008, 67 (2), 458-472.

(23) Cuiv, P. O.; Clarke, P.; O’Connell, M. Identification and characterization of an ironregulated gene, ChtA, required for the utilization of the xenosiderophores aerobactin, rhizobactin 1021 and schizokinen by Pseudomonas aeruginosa. Microbiology 2006, 152 (Pt 4), 945-954. https://doi.org/10.1099/mic.0.28552-0.

(24) Marshall, B.; Stintzi, A.; Gilmour, C.; Meyer, J.-M.; Poole, K. Citrate-mediated iron uptake in Pseudomonas aeruginosa: involvement of the citrate-inducible FecA receptor 
and the FeoB ferrous iron Transporter. Microbiology (Reading, Engl.) 2009, 155 (Pt 1), 305-315. https://doi.org/10.1099/mic.0.023531-0.

(25) Llamas, M. A.; Sparrius, M.; Kloet, R.; Jimenez, C. R.; Vandenbroucke-Grauls, C.; Bitter, W. The heterologous siderophores ferrioxamine B and ferrichrome activate signaling pathways in Pseudomonas aeruginosa. Journal of bacteriology 2006, 188 (5), $1882-1891$.

(26) Josts, I.; Veith, K.; Tidow, H. Ternary structure of the outer membrane transporter FoxA with resolved signalling domain provides insights into TonB-mediated siderophore uptake. eLife 2019, 8, e48528. https://doi.org/10.7554/eLife.48528.

(27) Müller, G.; Matzanke, B. F.; Raymond, K. N. Iron transport in Streptomyces pilosus mediated by ferrichrome siderophores, rhodotorulic acid, and enantio-rhodotorulic acid. J. Bacteriol. 1984, 160 (1), 313-318.

(28) Drechsel, H.; Winkelmann, G. In Transition Metals in Microbial Metabolism; Harwood Academic Publishers: Amsterdam, 1997; pp 1-49.

(29) Dean, C. R.; Poole, K. Expression of the ferric enterobactin receptor (PfeA) of Pseudomonas aeruginosa: involvement of a two-component regulatory system. Mol Microbiol 1993, 8 (6), 1095-1103.

(30) Michel, L.; Gonzalez, N.; Jagdeep, S.; Nguyen-Ngoc, T.; Reimmann, C. PchR-box recognition by the AraC-type regulator PchR of Pseudomonas aeruginosa requires the siderophore pyochelin as an effector. Molecular microbiology 2005, 58 (2), 495-509.

(31) Llamas, M. A.; Imperi, F.; Visca, P.; Lamont, I. L. Cell-surface signaling in Pseudomonas: stress responses, iron transport, and pathogenicity. FEMS microbiology reviews 2014, 38 (4), 569-597. https://doi.org/10.1111/1574-6976.12078.

(32) Gasser, V.; Baco, E.; Cunrath, O.; August, P. S.; Perraud, Q.; Zill, N.; Schleberger, C.; Schmidt, A.; Paulen, A.; Bumann, D.; Mislin, G. L. A.; Schalk, I. J. Catechol 
siderophores repress the pyochelin pathway and activate the enterobactin pathway in Pseudomonas aeruginosa: an opportunity for siderophore-antibiotic conjugates development. Environ. Microbiol. 2016, 18 (3), 819-832. https://doi.org/10.1111/14622920.13199.

(33) Anderegg, G.; L’Eplattenier, F.; Schwarzenbach, G. Hydroxamatkomplexe III. Eisen(III)-Austausch Zwischen Sideraminen Und Komplexonen. Diskussion der Bildungskonstanten der Hydroxamatkomplexe. Helvetica Chimica Acta 1963, 46 (4), 1409-1422. https://doi.org/10.1002/hlca.19630460436.

(34) Zähner, H.; Bachmann, E.; Hütter, R.; Nüesch, J. Sideramine, Eisenhaltige Wachstumsfaktoren aus Mikroorganismen. PAT 1962, 25 (5), 708-736. https://doi.org/10.1159/000161327.

(35) Yamanaka, K.; Oikawa, H.; Ogawa, H.; Hosono, K.; Shinmachi, F.; Takano, H.; Sakuda, S.; Beppu, T.; Ueda, K. Desferrioxamine E produced by Streptomyces griseus stimulates growth and development of Streptomyces tanashiensis. Microbiology, 2005, 151 (9), 2899-2905. https://doi.org/10.1099/mic.0.28139-0.

(36) Essén, S. A.; Johnsson, A.; Bylund, D.; Pedersen, K.; Lundström, U. S. Siderophore production by Pseudomonas stutzeri under aerobic and anaerobic conditions. Appl. Environ. Microbiol. 2007, 73 (18), 5857-5864. https://doi.org/10.1128/AEM.00072-07.

(37) Berner, I.; Winkelmann, G. Ferrioxamine transport mutants and the identification of the ferrioxamine receptor protein (FoxA) in Erwinia herbicola (Enterobacter agglomerans). Biol Met 1990, 2 (4), 197-202. https://doi.org/10.1007/BF01141359.

(38) Beare, P. A.; For, R. J.; Martin, L. W.; Lamont, I. L. Siderophore-mediated cell signalling in Pseudomonas aeruginosa: divergent pathways regulate virulence factor production and siderophore receptor synthesis. Mol. Microbiol. 2003, 47 (1), 195-207. https://doi.org/10.1046/j.1365-2958.2003.03288.x. 
(39) Draper, R. C.; Martin, L. W.; Beare, P. A.; Lamont, I. L. Differential proteolysis of sigma regulators controls cell-surface signalling in Pseudomonas aeruginosa: Ppoteolysis in cell-surface signalling pathways. Molecular Microbiology 2011, 82 (6), 1444-1453. https://doi.org/10.1111/j.1365-2958.2011.07901.x.

(40) Lamont, I. L.; Beare, P. A.; Ochsner, U.; Vasil, A. I.; Vasil, M. L. Siderophore-mediated

(41) Spencer, M. R.; Beare, P. A.; Lamont, I. L. Role of cell surface signaling in proteolysis of an alternative sigma factor in Pseudomonas aeruginosa. J. Bacteriol. 2008, 190 (14), 4865-4869. https://doi.org/10.1128/JB.01998-07.

(42) Shirley, M.; Lamont, I. L. Role of TonB1 in pyoverdine-mediated Ssignaling in Pseudomonas aeruginosa. J. $\quad$ Bacteriol. 2009, $191 \quad$ (18), 5634-5640. https://doi.org/10.1128/JB.00742-09.

(43) Draper, R. C.; Martin, L. W.; Beare, P. A.; Lamont, I. L. Differential proteolysis of sigma regulators controls cell-surface signalling in Pseudomonas aeruginosa. Mol. Microbiol. 2011, 82 (6), 1444-1453. https://doi.org/10.1111/j.1365-2958.2011.07901.x.

(44) Edgar, R. J.; Xu, X.; Shirley, M.; Konings, A. F.; Martin, L. W.; Ackerley, D. F.; Lamont, I. L. Interactions between an anti-sigma protein and two sigma factors that regulate the pyoverdine signaling pathway in Pseudomonas aeruginosa. BMC Microbiol. 2014, 14, 287. https://doi.org/10.1186/s12866-014-0287-2.

(45) Bishop, T. F.; Martin, L. W.; Lamont, I. L. Activation of a cell surface signaling pathway in Pseudomonas aeruginosa requires ClpP protease and new sigma factor synthesis. Front Microbiol 2017, 8, 2442. https://doi.org/10.3389/fmicb.2017.02442. 
1 (46) Edgar, R. J.; Hampton, G. E.; Garcia, G. P. C.; Maher, M. J.; Perugini, M. A.; Ackerley, D. F.; Lamont, I. L. Integrated activities of two alternative sigma factors coordinate iron acquisition and uptake by Pseudomonas aeruginosa. Mol. Microbiol. 2017, 106 (6), 891904. https://doi.org/10.1111/mmi.13855.

(47) Casas Garcia, G. P.; Perugini, M. A.; Lamont, I. L.; Maher, M. J. The Purification of the $\Sigma F p v I / F p v R 20$ and $\Sigma$ PvdS/FpvR20 protein complexes is facilitated at room temperature. Protein Expr. Purif. 2019, 160, 11-18. https://doi.org/10.1016/j.pep.2019.03.005.

(48) Brandel, J.; Humbert, N.; Elhabiri, M.; Schalk, I. J.; Mislin, G. L. A.; Albrecht-Garry, A.-M. Pyochelin, a siderophore of Pseudomonas aeruginosa: physicochemical characterization of the Iron(III), Copper(II) and Zinc(II) complexes. Dalton Trans 2012, $41(9), 2820-2834$.

(49) Albrecht-Gary, A. M.; Blanc, S.; Rochel, N.; Ocacktan, A. Z.; Abdallah, M. A. Bacterial iron transport: coordination properties of pyoverdin $\mathrm{PaA}$, a peptidic siderophore of Pseudomonas aeruginosa. Inorg. Chem. 1994, 33, 6391-6402.

(50) Clément, E.; Mesini, P. J.; Pattus, F.; Abdallah, M. A.; Schalk, I. J. The binding mechanism of pyoverdin with the outer membrane receptor FpvA in Pseudomonas aeruginosa is dependent on its iron-loaded status. Biochemistry 2004, 43, 7954-7965.

(51) Cunrath, O.; Geoffroy, V. A.; Schalk, I. J. Metallome of Pseudomonas aeruginosa: a role for siderophores. Environ. Microbiol. 2016, $18 \quad$ (10), 3258-3267. https://doi.org/10.1111/1462-2920.12971.

(52) Winsor, G. L.; Griffiths, E. J.; Lo, R.; Dhillon, B. K.; Shay, J. A.; Brinkman, F. S. L. Enhanced annotations and Ffatures for comparing thousands of Pseudomonas genomes in the Pseudomonas genome database. Nucleic Acids Res. 2016, 44 (D1), D646-653. https://doi.org/10.1093/nar/gkv1227. 
1 (53) Meyer, J. M.; Abdallah, M. A. The fluorescent pigment of Pseudomonas fluorescens: biosynthesis, purification and physicochemical Properties. J Gen Microbiol 1978, 107, $319-328$.

(54) Vizcaíno, J. A.; Csordas, A.; del-Toro, N.; Dianes, J. A.; Griss, J.; Lavidas, I.; Mayer, G.; Perez-Riverol, Y.; Reisinger, F.; Ternent, T.; Xu, Q.-W.; Wang, R.; Hermjakob, H. 2016 Update of the PRIDE database and its related tools. Nucleic Acids Res. 2016, 44 (D1), D447-456. https://doi.org/10.1093/nar/gkv1145.

(55) Kabsch, W. XDS. Acta Crystallogr D Biol Crystallogr 2010, 66 (Pt 2), 125-132. https://doi.org/10.1107/S0907444909047337.

(56) Evans, P. Scaling and assessment of data quality. Acta Crystallogr. D Biol. Crystallogr. 2006, 62 (Pt 1), 72-82. https://doi.org/10.1107/S0907444905036693.

(57) Evans, P. R. An introduction to data reduction: space-group determination, scaling and intensity statistics. Acta Crystallogr. D Biol. Crystallogr. 2011, 67 (Pt 4), 282-292. https://doi.org/10.1107/S090744491003982X.

(58) Tickle, I. J.; Flensburg, C.; Keller, P.; Paciorek, W.; Sharff, A.; Vonrheim, C.; Bricogne, G. STARANISO. Cambridge, United Kingdom: Global Phasing Ltd. 2018.

(59) McCoy, A. J.; Grosse-Kunstleve, R. W.; Adams, P. D.; Winn, M. D.; Storoni, L. C.; Read, R. J. Phaser crystallographic software. J Appl Crystallogr 2007, 40 (Pt 4), 658674. https://doi.org/10.1107/S0021889807021206.

(60) Murshudov, G. N.; Skubák, P.; Lebedev, A. A.; Pannu, N. S.; Steiner, R. A.; Nicholls, R. A.; Winn, M. D.; Long, F.; Vagin, A. A. REFMAC5 for the refinement of macromolecular crystal structures. Acta Crystallogr. D Biol. Crystallogr. 2011, 67 (Pt 4), 355-367. https://doi.org/10.1107/S0907444911001314.

(61) Afonine, P. V.; Grosse-Kunstleve, R. W.; Echols, N.; Headd, J. J.; Moriarty, N. W.; Mustyakimov, M.; Terwilliger, T. C.; Urzhumtsev, A.; Zwart, P. H.; Adams, P. D. 
1 Towards automated crystallographic structure refinement with Phenix.Refine. Acta 2 Crystallogr. D $\quad$ Biol. Crystallogr. 2012, $68 \quad(\mathrm{Pt} 4), \quad 352-367$. 3 https://doi.org/10.1107/S0907444912001308.

4 (62) Hannauer, M.; Barda, Y.; Mislin, G. L.; Shanzer, A.; Schalk, I. J. The ferrichrome uptake 5 pathway in Pseudomonas aeruginosa involves an iron release mechansim with acylation 6 of the siderophore and a recycling of the modified desferrichrome. J Bacteriol 2010, 192, 7 1212-1220. https://doi.org/10.1128/JB.01539-09. 
1 TABLE

2

3 Table 1. Data collection and refinement statistics

\begin{tabular}{|c|c|}
\hline & $\begin{array}{c}\text { FoxA-nocardamine } \\
\text { complex } \\
\text { (pdb: 6Z8A) }\end{array}$ \\
\hline \multicolumn{2}{|l|}{ Data collection } \\
\hline Beamline & PETRA III, P14 \\
\hline Space group & $\mathrm{P} 3{ }_{2} 21$ \\
\hline \multicolumn{2}{|l|}{ Cell dimensions } \\
\hline$a, b, c(\AA)$ & $95.2,95.2,178.65$ \\
\hline$\alpha, \beta, \gamma\left({ }^{\circ}\right)$ & $90,90,90$ \\
\hline Resolution $(\AA)$ & $82.465-2.95(3.1-2.95)$ \\
\hline$R_{\text {merge }}$ & $0.18(2.58)$ \\
\hline$R_{\text {meas }}$ & $0.185(2.64)$ \\
\hline$I / \sigma I$ & $12.8(1.4)$ \\
\hline$C C_{1 / 2}$ & $0.99(0.697)$ \\
\hline Completeness ( $\%)$ & $94(99)$ \\
\hline Redundancy & $20(19.8)$ \\
\hline \multicolumn{2}{|l|}{ Refinement } \\
\hline Resolution $(\AA)$ & 2.95 \\
\hline No. reflections & $14984(750)$ \\
\hline$R_{\text {work }} / R_{\text {free }}$ & $0.23 / 0.27$ \\
\hline No. atoms & 5396 \\
\hline Protein & 5340 \\
\hline Ligand/ion & 48 \\
\hline Water & 8 \\
\hline \multicolumn{2}{|l|}{$B$-factors } \\
\hline Protein & 65.3 \\
\hline Ligand/ion & 68.2 \\
\hline \multicolumn{2}{|l|}{ R.m.s. deviations } \\
\hline Bond lengths $(\AA)$ & 0.012 \\
\hline Bond angles $\left(^{\circ}\right)$ & 2.056 \\
\hline
\end{tabular}




\section{FIGURE LEGENDS}

2 Figure 1. Chemical structures of siderophores. a) Desferrioxamine E or nocardamine

3 (NOCA), (b) desferrioxamine B (DFOB), and (c) desferrichrome (FRC). Ferric iron is chelated

4 at a 1:1 stoichiometry by these three siderophores. The functional groups involved in iron

5 chelation for each siderophore are shown in red. Affinities of the siderophores for iron are:

$6 \quad$ NOCA, $10^{32} \mathrm{M}^{-1}$; DFOB, $10^{30} \mathrm{M}^{-1}$, and FRC, $10^{29} \mathrm{M}^{-1} .33$

7

8 Figure 2. Modulation of the expression of proteins involved in iron acquisition in $P$. 9 aeruginosa PAO1 cells grown in CAA medium in the presence of NOCA or DFOB. a) and

10 b) Proteomic analyses were performed on $P$. aeruginosa PAO1 cells grown for $8 \mathrm{~h}$ in CAA 11 medium, with or without $10 \mu \mathrm{M}$ NOCA (a) or DFOB (b). The average values measured in CAA 12 without siderophores were plotted against the average values in CAA supplemented with the 13 siderophores. c) and d) and e) Heat maps of various proteins involved in the PCH (d) and PVD 14 (e) pathways and of TBDTs (c): the darker the shade of green, the higher the expression of the 15 protein is induced; the darker the shade of red, the stronger the expression of protein is 16 repressed. Only the proteins for which a change in the level of expression was observed are 17 shown. Proteins not detected in the three experiments are represented in grey; NS: 18 nonsignificant; ${ }^{*} \mathrm{p}<0.05$, ${ }^{* *} \mathrm{p}<0.01$, and ${ }^{* * *} \mathrm{p}<0.001$. Sup Data 1 shows the detailed results of protein identification and quantitation. Supplementary Figure 1 shows these proteomic data 20 (volcano plots) considering the $\log 10$ of the adjusted $\mathrm{p}$ value. The results for FRC were obtained 21 in Perraud et al. $2020 .^{9}$

Figure 3. Modulation of the transcription of genes encoding TBDTs involved in iron acquisition in $P$. aeruginosa cells when grown with or without NOCA (a) or DFOB (b). $P$. aeruginosa PAO1 was grown as for the proteomic analyses, with or without $10 \mu \mathrm{M}$ NOCA (a) 
1 or DFOB (b). Gene transcription was normalized to that of the $u v r D$ reference gene. The results

2 show the ratio between the values obtained in the presence of the siderophore over those

3 obtained in the absence of the siderophore. $f p t A$ encodes the TBDT of PCH, fpvA that of PVD,

$4 p f e A$ that of enterobactin, $f v b A$ that of vibriobactin, femA that of mycobactin and 5 carboxymycobactin, fiuA that of FRC, foxA that of DFO-B, fec $A$ that of citrate, and PA0434 a 6 hypothetical TBDT. The data show the mean of three independent experiments.

8 Figure 4. ${ }^{55} \mathrm{Fe}$ uptake by $\triangle p v d F \Delta p c h A, \Delta p v d F \Delta p c h A \Delta f o x A, \triangle p v d F \Delta p c h A \Delta f i u A$, and $\triangle p v d F \Delta p c h A \Delta f i u A \Delta f o x A$ cells in the presence of NOCA (a), DFOB (b), or FRC (c). The strains were grown in CAA medium supplemented with one of the siderophores (NOCA, 11 DFOB, or FRC) to induce the expression of the corresponding uptake pathway. Then, bacteria 12 were harvested and incubated in $50 \mathrm{mM}$ Tris- $\mathrm{HCl} \mathrm{pH} 8.0$ in the presence of $200 \mathrm{nM}$ of the ${ }^{55} \mathrm{Fe}-$ 13 siderophore complexes. Aliquots were removed at various times, the bacteria pelleted, and the 14 radioactivity retained in the cells measured. In each panel, transport in $\triangle p v d F \triangle p c h A$ cells is 15 shown in red, that in $\triangle p v d F \triangle p c h A \triangle f o x A$ in blue, that in $\triangle p v d F \triangle p c h A \triangle f i u A$ in green, and that 16 in $\triangle p v d F \triangle p c h A \triangle f i u A \Delta f o x A$ in black. For each siderophore, the uptake assays with $\triangle p v d F \Delta p c h A$ 17 cells were also performed in the presence of the protonophore CCCP (orange curve) to 18 differentiate proton-motive force dependent transport from diffusion. For each curve, the data 19 represent the mean of three independent experiments.

21 Figure 5. Growth of $\triangle p v d F \Delta p c h A, \triangle p v d F \Delta p c h A \Delta f o x A$, and $\triangle p v d F \Delta p c h A \Delta f i u A$ strains 22 with or without NOCA, DFOB, or FRC. The $\triangle p v d F \Delta p c h A$ (red curve) and $23 \Delta p v d F \triangle p c h A \triangle f o x A$ (blue curve) strains were grown in CAA medium, with (a) or without 10 $24 \mu \mathrm{M}$ NOCA (b) or DFOB (c). The $\triangle p v d F \Delta p c h A$ (red curve) and $\triangle p v d F \Delta p c h A \Delta f i u A$ (green curve) strains were grown in CAA medium supplemented (e) or not (d) with $10 \mu \mathrm{M}$ FRC. 
1 Growth was followed by monitoring optical density at $600 \mathrm{~nm}$. The results are representative

2 of three independent experiments.

3

4

Figure 6. Overall structure and siderophore coordination of the FoxA-NOCA complex. a) Cutaway-view of FoxA with $\mathrm{Fe}^{3+}$-NOCA located in the binding pocket. b) Detailed view of the NOCA-binding pocket with interacting residues shown as sticks. c) Polder omit showing electron density for $\mathrm{Fe}^{3+}$-NOCA.

Figure 7. Interactions between FoxA and NOCA-Fe. a) Position of the ferri-NOCA and ferriDFOB siderophores in the FoxA binding site. Red sphere, ferric iron ion; NOCA in green, and DFOB in blue. b) Fluorescence titration experiments with NOCA fitted using a single-site binding model (left) yield a $\mathrm{K}_{\mathrm{d}}$ of $178 \pm 16 \mathrm{nM}$. Raw emission spectra (right) showing the quenching of Trp fluorescence by titration of NOCA.

Figure 8. Proposed model of NOCA, DFOB and FRC dependent iron uptake pathways in P. aeruginosa. Ferri-NOCA is transported across the outer membrane exclusively by FoxA TBDT, whereas ferri-DFOB is transported by FoxA and another unidentified TBDT. Both ferriNOCA and ferri-DFOB induce the transcription and expression of fox $A$ via the sigma and antisigma (FoxI/FoxR) dependent mechanism. How iron is released from these two siderophores and transported into the bacterial cytoplasm is still unknown. Ferri-FRC is transported across the outer membrane by FiuA and another unidentified TBDT. Once in the periplasm, Ferri$\mathrm{FRC}$ is transported further across the inner membrane by the permease FiuB. ${ }^{62}$ Iron is released from FRC by a mechanism involving the acetylation of FRC by FiuE and reduction by an unidentified reductase. ${ }^{62}$ Ferri-FRC induces the transcription and expression of $f i u A^{22}$ and likely that of fiuB and fiuE via the sigma and anti-sigma (FiuI/FiuR) dependent mechanism. The inner 
1

2

4

7

8

9

10

11

12

13

14

15

16

17

18

19

20

21

22

23

24

25

26

27

28

29

30

31

32

33

34

35

36

37

38

39

40

41

42

43

44

45

46

47

48

49

50

51

52

53

54

55

56

57

58

59

60

1 membrane complex TonB-ExbBD provides the energy for uptake by the TBDTs in all pathways

2 presented in the figure. ${ }^{5}$

3

4

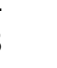

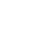

8

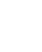

.


A
B

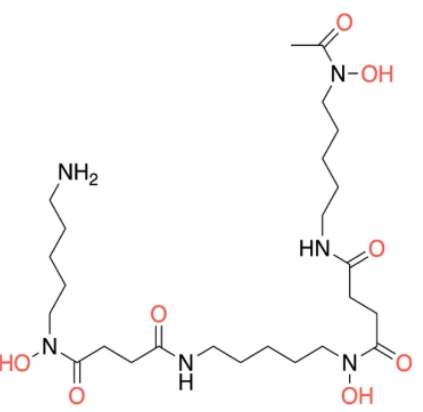

Desferrioxamine B (DFOB)

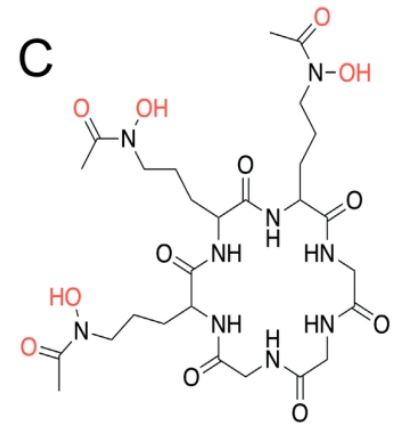

Desferrichrome (FRC)

Figure 1. Chemical structures of siderophores. (A) Nocardamine (NOCA) or desferrioxamine $E,(B)$ desferrioxamine $B$ (DFOB), and (C) desferrichrome (FRC). Ferric iron is chelated at a $1: 1$ stoichiometry by these three siderophores. The functional groups involved in iron chelation for each siderophore are shown in red. Affinities of the siderophores for iron are: NOCA, $10^{32} \mathrm{M}^{-1}$; DFOB, $10^{30} \mathrm{M}^{-1}$, and FRC, $10^{29} \mathrm{M}^{-1} .34$

$159 \times 60 \mathrm{~mm}(300 \times 300 \mathrm{DPI})$ 


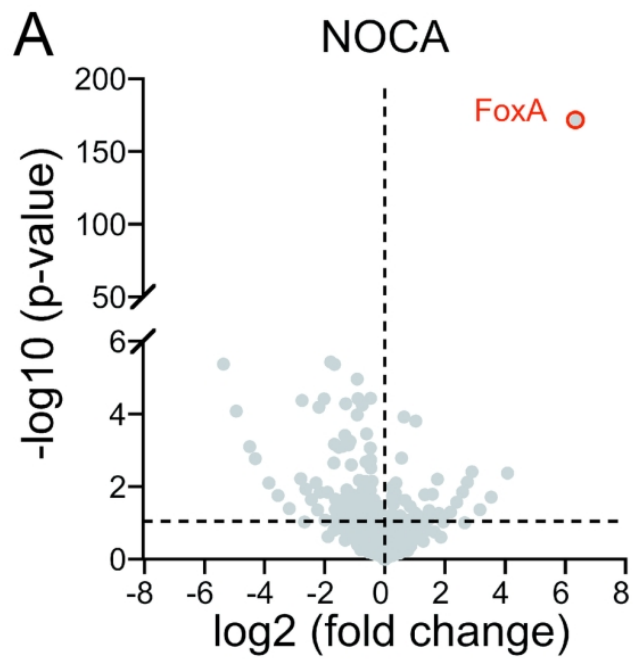

C

TBDTs

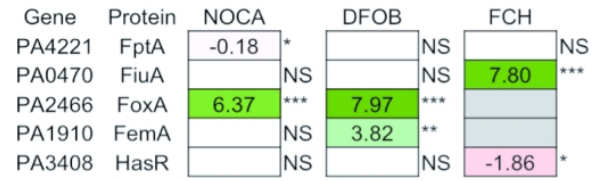

$E_{\text {PVD pathway }}$

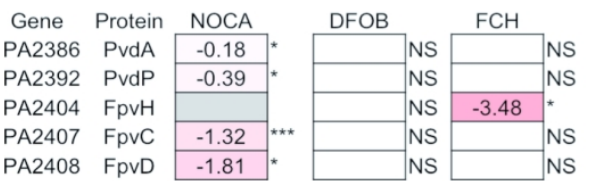

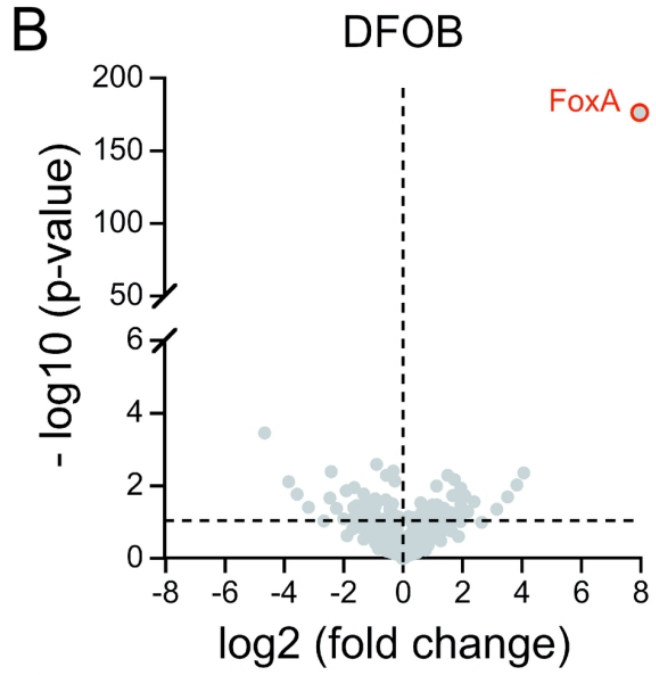

D
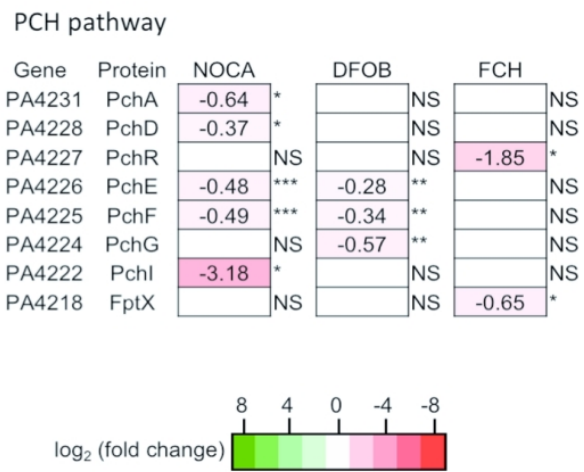

Figure 2. Modulation of the expression of proteins involved in iron acquisition in $P$. aeruginosa PAO1 cells grown in CAA medium in the presence of NOCA or DFOB. A and B. Proteomic analyses were performed on $P$. aeruginosa PAO1 cells grown for $8 \mathrm{~h}$ in CAA medium, with or without $10 \mu \mathrm{M}$ NOCA (A) or DFOB (B). The average values measured in CAA without siderophores were plotted against the average values in CAA supplemented with the siderophores. C, D, and E. Heat maps of various proteins involved in the $P C H$ (D) and PVD (E) pathways and of TBDTs (C): the darker the shade of green, the more expression of the protein is induced. Only the proteins for which a change in the level of expression was observed are shown. Proteins not detected in the three experiments are represented in grey; NS: nonsignificant; $* p<0.05, * * p<0.01$, and $* * * p<0.001$. Sup Data 1 shows the detailed results of protein identification and quantitation. Figure SM1 shows these proteomic data (volcano plots) considering the log10 of the adjusted $p$ value. The results for FCH were obtained in Perraud et al. 2020.10

$159 \times 153 \mathrm{~mm}(300 \times 300 \mathrm{DPI})$ 

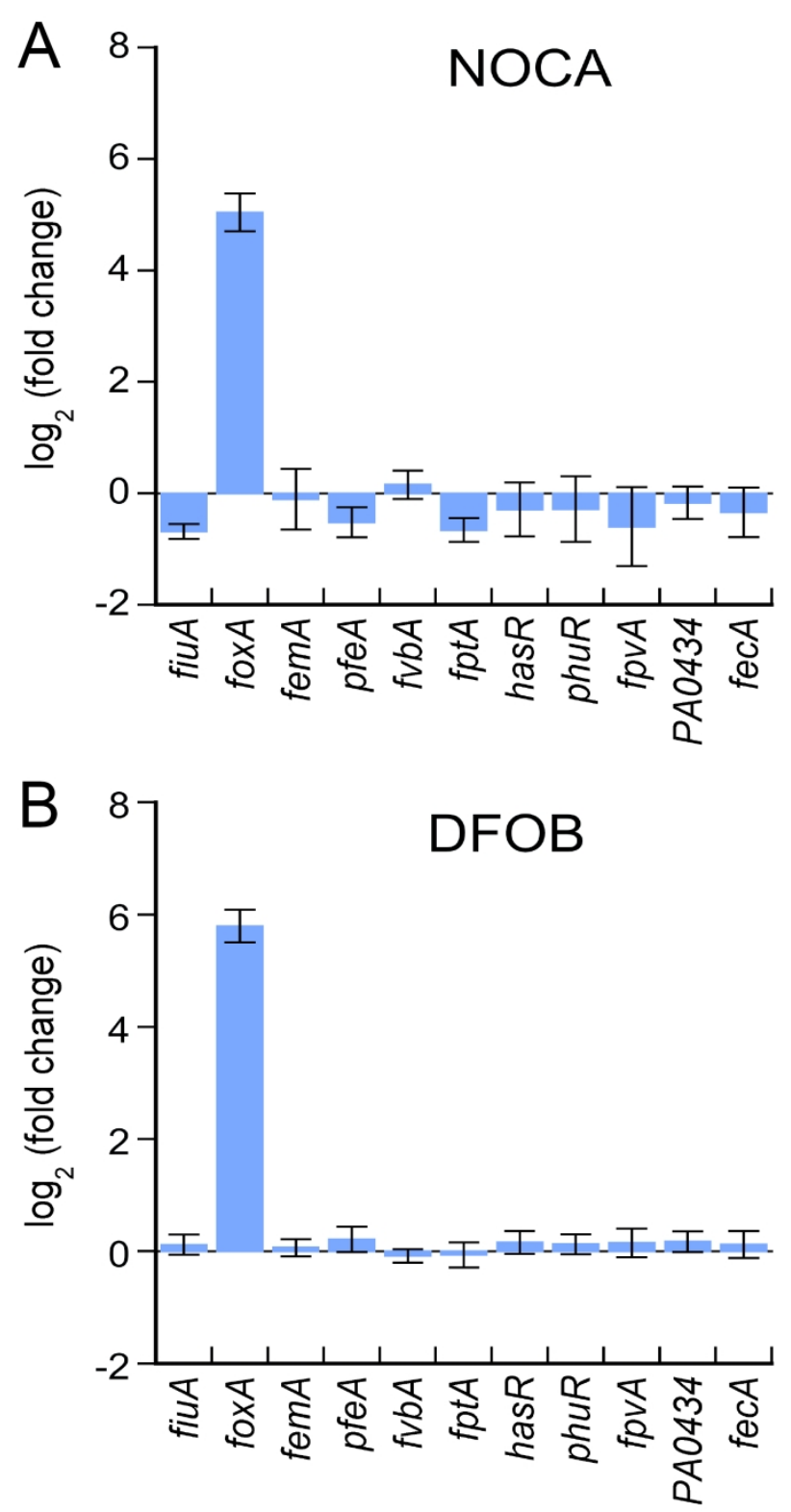

Figure 3. Modulation of the transcription of genes encoding TBDTs involved in iron acquisition in $P$. aeruginosa cells when grown with or without NOCA (A) or DFOB (B). P. aeruginosa PAO1 was grown as for the proteomic analyses, with or without $10 \mu \mathrm{M}$ NOCA (A) or DFOB (B). Gene transcription was normalized to that of the $u v r D$ reference gene. The results show the ratio between the values obtained in the presence of the siderophore over those obtained in the absence of the siderophore. $f p t A$ encodes the TBDT of PCH, fpvA that of PVD, pfeA that of enterobactin, $f v b A$ that of vibriobactin, femA that of mycobactin and carboxymycobactin, fiuA that of FERRI, foxA that of DFO-B, fecA that of citrate, and PA0434 a hypothetical TBDT. The data show the mean of three independent experiments. 


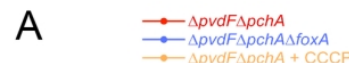

B $\because-\triangle D V D F A D C h A A$

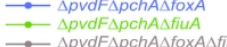

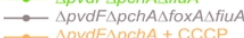
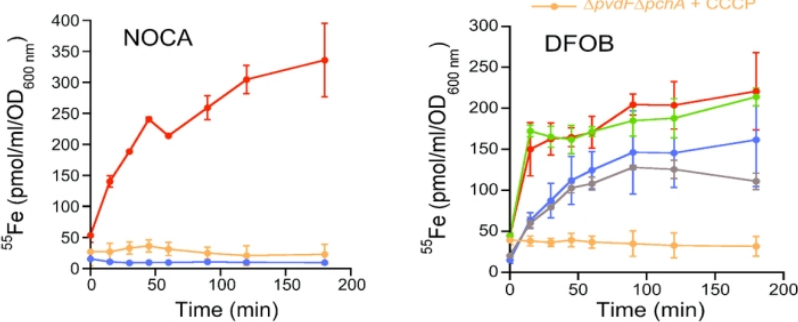

C $\quad \because \quad \triangle P V d F \perp D C h A A$ $\because \Delta$ DVdFApChAANIIUA

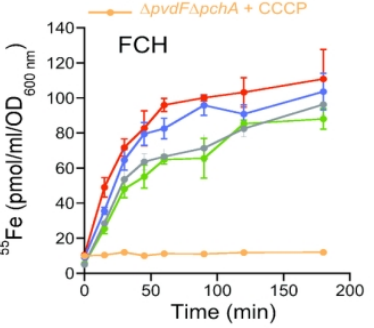

Figure $4 .{ }^{55} \mathrm{Fe}$ uptake by $\triangle p v d F \Delta p c h A, \triangle p v d F \Delta p c h A \Delta f o x A, \triangle p v d F \Delta p c h A \triangle$ fiuA, and $\triangle p v d F \Delta p c h A \Delta f i u A \Delta$ foxA cells in the presence of NOCA (A), DFOB (B), or FRC (C). The strains were grown in CAA medium supplemented with one of the siderophores (NOCA, DFOB, or FRC) to induce the expression of the corresponding uptake pathway. Then, bacteria were harvested and incubated in $50 \mathrm{mM}$ Tris $-\mathrm{HCl} \mathrm{pH} 8.0$ in the presence of $200 \mathrm{nM}$ of the ${ }^{55} \mathrm{Fe}$-siderophore complexes. Aliquots were removed at various times, the bacteria pelleted, and the radioactivity retained in the cells measured. In each panel, transport in $\triangle p v d F \triangle p c h A$ cells is shown in red, that in $\triangle p v d F \triangle p c h A \triangle f o x A$ in blue, that in $\triangle p v d F \triangle p c h A \triangle$ fiuA in green, and that in $\triangle p v d F \Delta p c h A \triangle f i u A \Delta f o x A$ in black. For each siderophore, the uptake assays with $\triangle p v d F \triangle p c h A$ cells were also performed in the presence of the protonophore CCCP (orange curve) to differentiate protonmotive force dependent transport from diffusion. For each curve, the data represent the mean of three independent experiments.

$160 \times 51 \mathrm{~mm}(300 \times 300 \mathrm{DPI})$ 

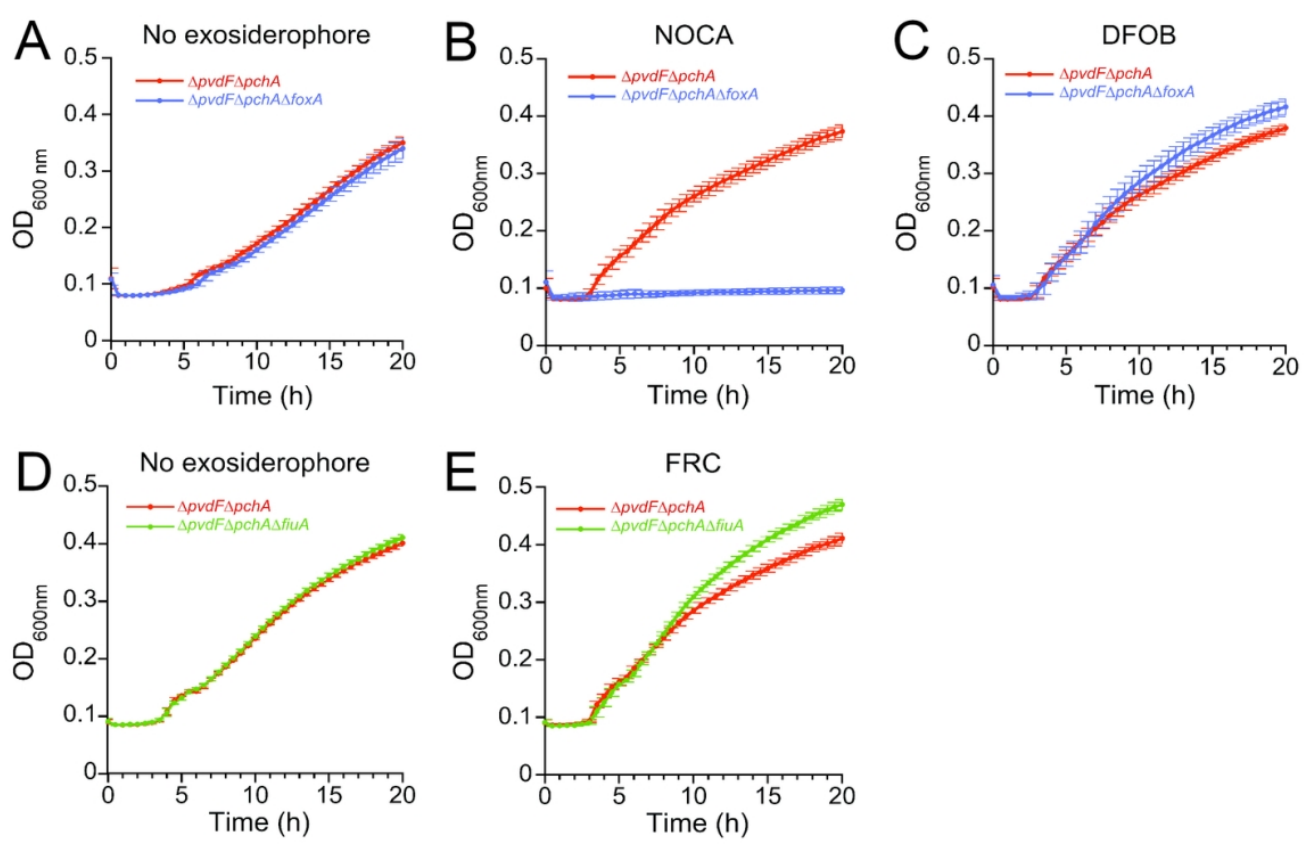

Figure 5. Growth of $\triangle p v d F \Delta p c h A, \triangle p v d F \triangle p c h A \triangle f o x A$, and $\triangle p v d F \Delta p c h A \triangle$ fiuA strains with or without NOCA, $\mathrm{DFOB}$, or FRC. The $\triangle p v d F \triangle p c h A$ (red curve) and $\triangle p v d F \triangle p c h A \triangle$ foxA (blue curve) strains were grown in CAA medium, with (A) or without $10 \mu \mathrm{M}$ NOCA (B) or DFOB (C). The $\triangle p v d F \triangle p c h A$ (red curve) and $\triangle p v d F \Delta p c h A \triangle$ fiuA (green curve) strains were grown in CAA medium supplemented (E) or not (D) with $10 \mu M$ FRC. Growth was followed by monitoring optical density at $600 \mathrm{~nm}$. The results are representative of three independent experiments.

$119 \times 76 \mathrm{~mm}(300 \times 300 \mathrm{DPI})$ 


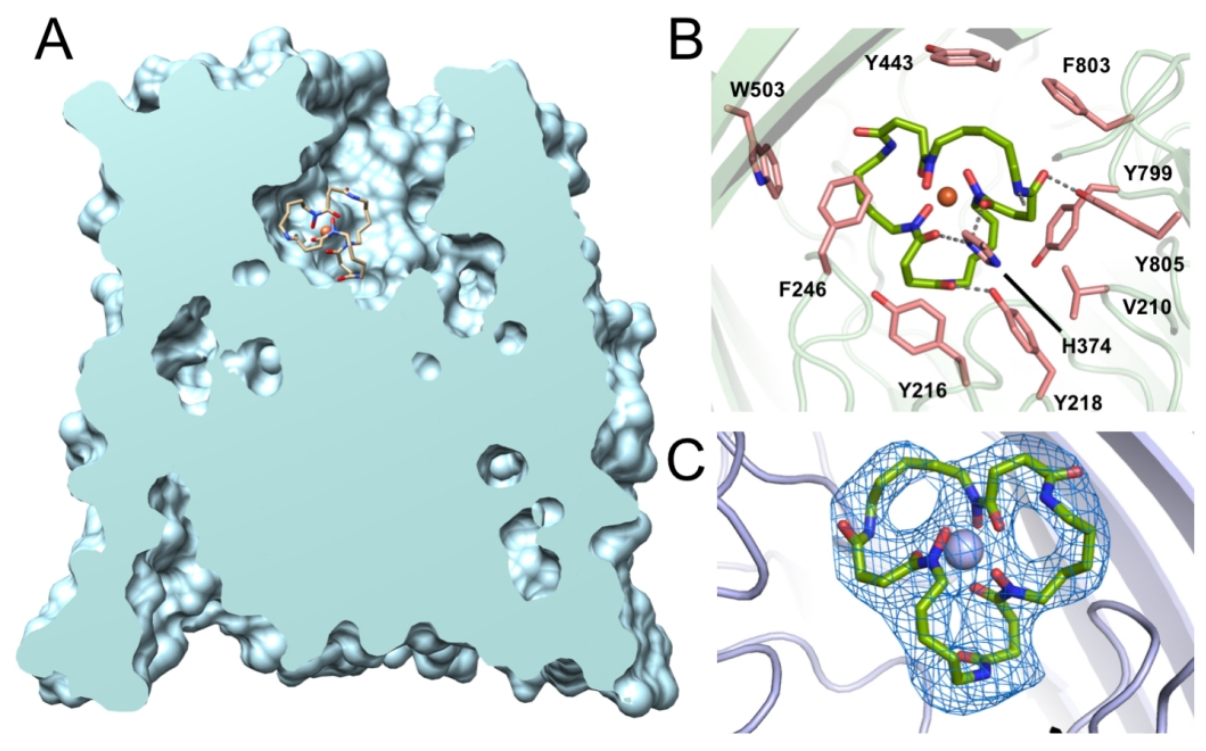

Figure 6. Overall structure and siderophore coordination of the FoxA-NOCA complex. A. Cutaway-view of FoxA with $\mathrm{Fe}^{3+}$-NOCA located in the binding pocket. B. Detailed view of the NOCA-binding pocket with interacting residues shown as sticks. C. Polder omit showing electron density for Fe ${ }^{3+}$-NOCA.

$159 \times 99 \mathrm{~mm}(247 \times 247$ DPI $)$ 

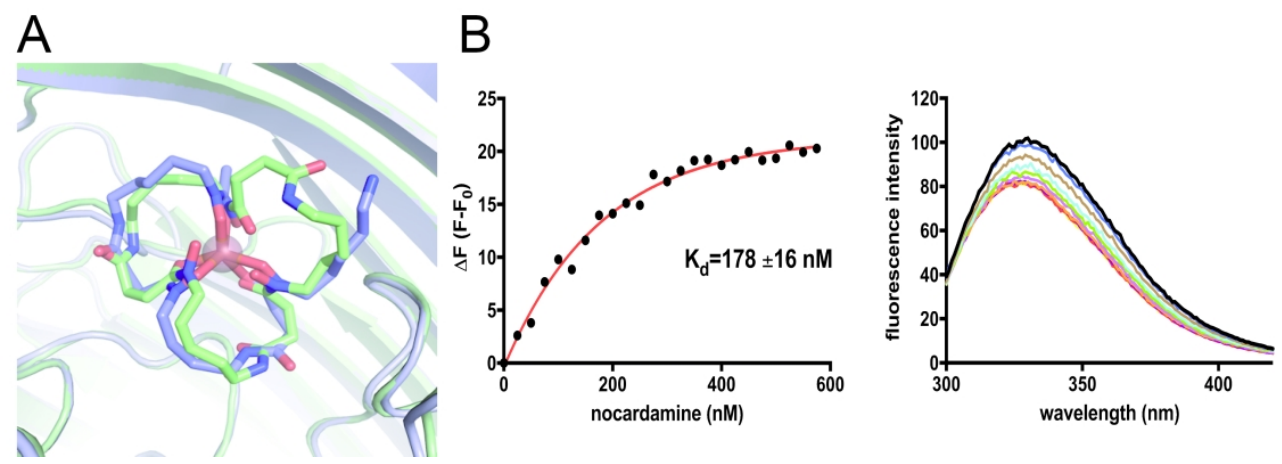

Figure 7. Interactions between FoxA and NOCA-Fe. A. Position of the ferri-NOCA and ferri-DFOB siderophores in the FoxA binding site. Red sphere, ferric iron ion; NOCA in green, and DFOB in blue. B. Fluorescence titration experiments with NOCA fitted using a single-site binding model (left) yield a Kd of 178 $\pm 16 \mathrm{nM}$. Raw emission spectra (right) showing the quenching of Trp fluorescence by titration of NOCA. 


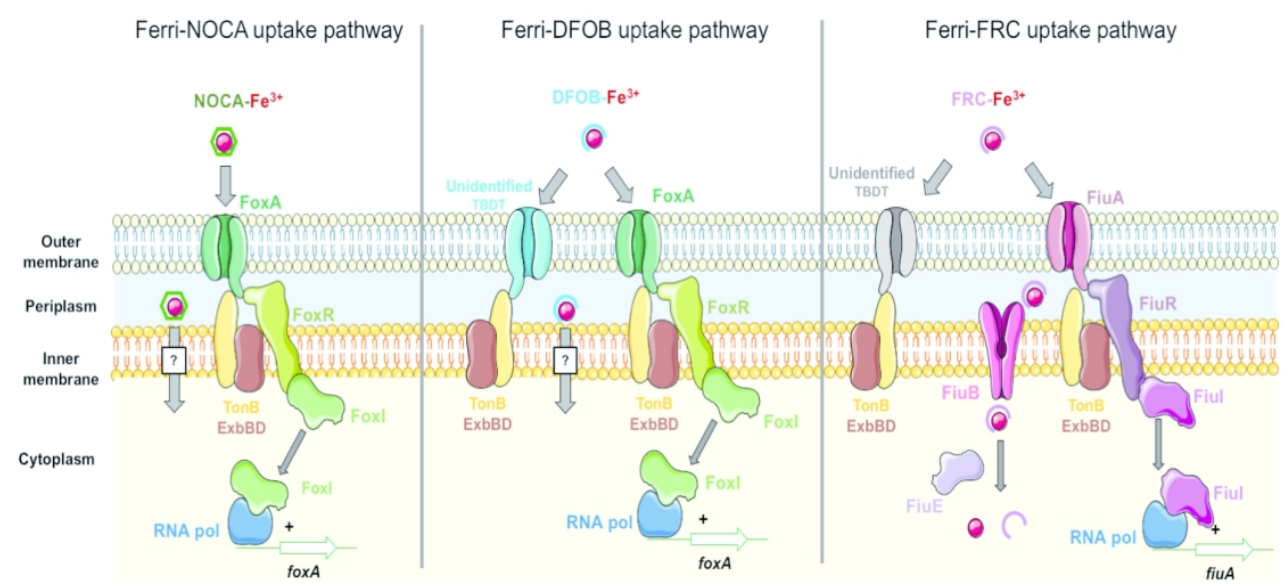

Figure 8. Proposed model of NOCA, DFOB and FRC dependent iron uptake pathways in $P$. aeruginosa. FerriNOCA is transported across the outer membrane exclusively by FoxA TBDT, whereas ferri-DFOB is transported by FoxA and another unidentified TBDT. Both ferri-NOCA and ferri-DFOB induce the transcription and expression of foxA via the sigma and anti-sigma (FoxI/FoxR) dependent mechanism. How iron is released from these two siderophores and transported into the bacterial cytoplasm is still unknown. FerriFRC is transported across the outer membrane by FiuA and another unidentified TBDT. Once in the periplasm, Ferri-FRC is transported further across the inner membrane by the permease FiuB. ${ }^{43}$ Iron is released from FRC by a mechanism involving the acetylation of FRC by FiuE and reduction by an unidentified reductase. ${ }^{43}$ Ferri-FRC induces the transcription and expression of fiuA 23 and likely that of fiuB and fiuE via the sigma and anti-sigma (FiuI/FiuR) dependent mechanism. The inner membrane complex TonB-ExbBD provides the energy for uptake by the TBDTs in all pathways presented in the figure 6 .

$160 \times 71 \mathrm{~mm}(300 \times 300 \mathrm{DPI})$ 

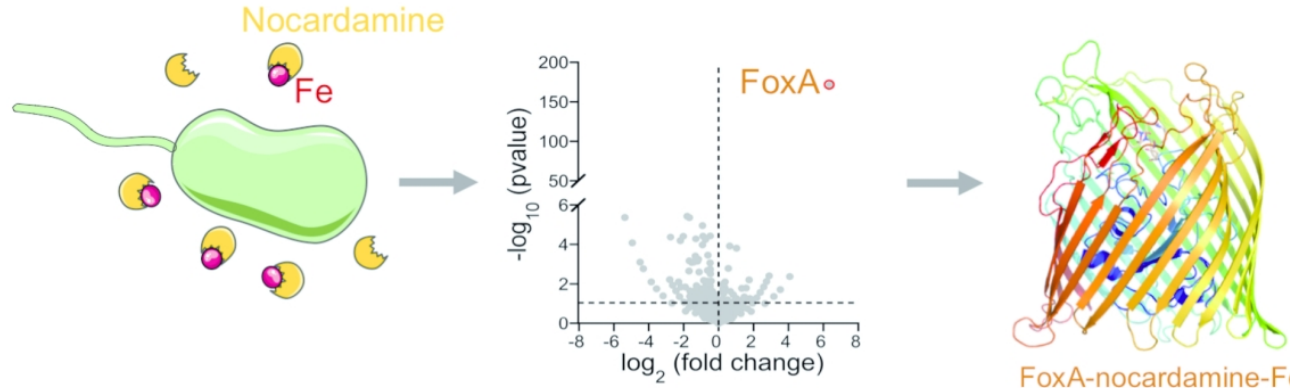

FoxA-nocardamine-Fe

The presence of nocardamine-Fe induces the expression of the transporter FoxA in $P$. aeruginosa cells $159 \times 79 \mathrm{~mm}(300 \times 300$ DPI $)$ 